\title{
Framing periodístico sobre el aborto en el Perú (2015-2019): un análisis comparativo entre la prensa de las regiones Lima metropolitana y Piura
}

\author{
Journalistic framing on abortion in Peru (2015-2019): a \\ comparative analysis between the press of the metropolitan \\ Lima and Piura regions
}

\author{
García Romero, E., Huamán Flores, F. y Palomino Moreno, H. W. ${ }^{1}$ \\ Recibido: 16-04-2021 - Aceptado: 15-08-2021 \\ https://doi.org/10.26441/RC20.2-2021-A10
}

\begin{abstract}
RESUMEN: Este artículo muestra los resultados de una investigación académica sobre el modo en que la prensa peruana aborda el tema del aborto. Se ha realizado un análisis de contenido para detectar los encuadres, los temas y las fuentes periodísticas presentes en 160 textos publicados en el quinquenio 2015-2019 por los diarios El Comercio, Perú 21, La República, La Hora, Correo y El Tiempo. Los tres primeros forman parte de la prensa más leída en la región de Lima metropolitana, mientras que los tres últimos están entre los diarios más leídos en la región de Piura. Estas dos regiones son las más pobladas del país andino. Una de las variables del análisis de contenido son los encuadres genéricos utilizados por la prensa: provida, proaborto y neutro/ambiguo. Los resultados muestran que cinco de los seis diarios seleccionados -todos excepto El Comercio- utilizaron mayoritariamente encuadres provida, es decir, opuestos al aborto inducido. Por otra parte, los tres diarios que forman parte de la prensa más leída en la región de Piura utilizaron porcentualmente encuadres más provida que los tres diarios que forman parte de la prensa más leída en la región de Lima metropolitana. En cuanto al tipo de fuentes a las que recurrieron los periodistas para informar sobre el aborto, pertenecen mayoritariamente a los ámbitos político y religioso, mientras que las del ámbito científico quedaron relegadas a un tercer lugar.
\end{abstract}

Palabras clave: aborto; framing; encuadres periodísticos; Perú; prensa.

\begin{abstract}
This article shows the results of an academic research on the way in which the Peruvian press addresses the issue of abortion. A content analysis has been carried out to detect the frames, themes and journalistic sources present in 160 texts published during the five-year period 2015-2019 by the newspapers El Comercio, Perú 21, La República, La Hora, Correo and El Tiempo. The first three are part of the most read press in the metropolitan Lima region, while the last three are among the most read newspapers in the Piura region. These two regions are the most populated in the Andean country. One of the variables of the content analysis are the generic frames used by the press: pro-life, pro-abortion and neutral/ambiguous. The results show that five of the six selected newspapers -all except El Comercio-
\end{abstract}

\footnotetext{
${ }^{1}$ Enrique García Romero es Doctor en Comunicación Social (mención cum laude) por la Universidad San Pablo-CEU (Madrid) y Máster en Comunicación Institucional y Política por la Universidad Carlos III de Madrid. Es profesor de las asignaturas Investigación en Comunicación I y ll en la Facultad de Comunicación de la Universidad de Piura (Perú). enrique.garcia@udep.edu.pe, https://orcid.org/0000-0002-5572-3383

Fernando Huamán Flores es Doctor en Comunicación Pública con la distinción honorífica de doctor internacional por la Universidad de Navarra, ganador del Premio Extraordinario de Doctorado. Es director del Centro de Investigación en Opinión Pública y profesor de Teoría de la Comunicación y Opinión Pública en la Facultad de Comunicación de la Universidad de Piura. fernando.huaman@udep.edu.pe, https://orcid.org/0000-0003-0669-7294

Henry Wilfredo Palomino Moreno es Ingeniero Industrial y de Sistemas por la Universidad de Piura y profesor de las asignaturas Estadística y Sociología en la Facultad de Comunicación de la Universidad de Piura. henry.palomino@udep.edu.pe, https://orcid.org/0000-0002-5839-8184
} 
used mostly pro-life frames, that is, opposed to induced abortion. On the other hand, the three newspapers that are part of the most read press in the Piura region used more pro-life frames in percentage terms than the three newspapers that are part of the most read press in the metropolitan Lima region. Regarding the type of sources that journalists used to report on abortion, they mostly belong to the political and religious spheres, while those from the scientific sphere were relegated to third place.

Keywords: abortion; framing; news frames; Peru; press.

\section{Introducción}

La teoría del Encuadre -Framing en inglés- es una de las más relevantes de la investigación académica sobre medios de comunicación, opinión pública y comunicación política. Algunos autores consideran "probable que el framing permanezca entre los conceptos más importantes en la investigación contemporánea sobre los efectos mediáticos, puesto que ha generado una apreciable percepción sobre la supuesta facilidad con que medios de comunicación y actores políticos pueden usar mensajes enmarcados para influir en la opinión pública” (Leeper y Slothuus, 2019, p. 21).

Según la definición clásica de Entman (1993), "encuadrar es seleccionar algunos aspectos de una realidad percibida y darles mayor relevancia en un texto comunicativo, de manera que se promueva la definición de un problema determinado, una interpretación causal, una evaluación moral y/o una recomendación de tratamiento para el asunto descrito" (p. 52). En tal sentido, los encuadres o "esquemas interpretativos que se apliquen estarán definiendo la significación de la situación, cómo se la interpreta, cómo es comprendida" (Sánchez, 2013, p. 43).

Por otra parte, el framing no se entiende bien sin la dimensión cultural. Autores como Graber (1989) y Entman (1993) señalan que los encuadres se hallan en diversos lugares del proceso comunicativo: en el emisor o comunicador, en el texto, en el receptor y en la cultura en que aparece el mensaje. Los mensajes establecen significados que las audiencias comprenden en el marco de un determinado contexto cultural, en el que se dan unos significados compartidos. Si un encuadre periodístico está alineado con un principio cultural ampliamente aceptado, será más sencillo que dicho encuadre sea compartido socialmente.

Sin embargo, no siempre coinciden los encuadres noticiosos utilizados por los periodistas con los puntos de vista de sus audiencias, dada la libertad que el profesional de la información tiene o debería tener (Oh y Hudson, 2017). Tampoco tiene por qué ocurrir a la inversa, pues la interpretación de la realidad que realizan las audiencias frente a un hecho depende de su experiencia e interpretación personal, además de la selección interpretativa que realicen los medios de comunicación (Gamson, 1992).

El objeto de estudio de esta investigación ha sido el tratamiento otorgado por la prensa más leída en las regiones de Lima metropolitana y Piura a la cuestión del aborto, durante el periodo 2015 a 2019, ambos años incluidos. Los autores de esta investigación consideran que el aborto es un tema relevante, que puede ser abordado desde muchos puntos de vista: desde aspectos legales, sociales, biológicos, morales, religiosos, políticos, etcétera. Entre los trabajos recientemente publicados, se encuentra un estudio sobre aborto, violencia de género y activismo feminista (Ingrassia, 2020), y otro sobre el aborto y el origen de la vida (Morán, 2020). Sin embargo, hasta el momento, no se ha analizado el modo de enfocar el aborto por parte de la prensa peruana. Por ello, esta investigación resulta un aporte novedoso de interés académico.

El primer y principal objetivo ha sido averiguar qué tipo de encuadres periodísticos emplea la prensa peruana al informar u opinar sobre el aborto, y si dichos enfoques se corresponden con el modo de pensar de la población peruana. Otro objetivo ha consistido en detectar los temas presentes en los 
textos publicados sobre el aborto, así como los argumentos a favor o en contra existentes en dichos textos. Finalmente, se ha buscado averiguar a qué tipo de fuentes acudieron los autores de los textos al informar u opinar sobre el aborto. No es objetivo de esta investigación comparar los marcos informativos de los diarios con la cultura dominante en la sociedad peruana.

La cuestión del aborto genera división de opiniones en diferentes países. En Argentina, por ejemplo, a finales de 2020, el Senado legalizó el aborto por un estrecho margen de votos en sus dos cámaras parlamentarias, produciéndose una división en la población argentina, con manifestaciones y declaraciones a favor y en contra de dicha ley.

En el Perú, el aborto provocado es punible, excepto "cuando es el único medio para salvar la vida de la gestante o para evitar en su salud un mal grave y permanente" ${ }^{2}$. En el caso de embarazo por violación sexual o en el que exista un diagnóstico médico sobre probables graves taras físicas o psíquicas en el nonato, "el aborto será reprimido con pena privativa de libertad no mayor de tres meses"3.

El 26 de septiembre de 2014 fue presentado en el Congreso de la República del Perú el proyecto de ley $\mathrm{N}^{\circ} 3839-2014-\mathrm{IC}$, iniciativa legislativa -presentada por diversas entidades mediante la recogida de 64.261 firmas- que buscaba despenalizar "el aborto de casos de embarazos a consecuencia de una violación sexual, inseminación artificial o transferencia de óvulos no consentida" (Congreso de la República, 2015). Dicho proyecto de ley fue archivado por la Comisión de Justicia y Derechos Humanos del Congreso el 24 de noviembre de 2015. Unos meses después, el 3 de mayo de 2016, la Comisión de Constitución del Congreso rechazó reconsiderar el proyecto legislativo.

Si bien la legislación peruana sobre el aborto no ha variado en los últimos seis años, la citada iniciativa legislativa recibió abundante cobertura informativa en los medios de comunicación peruanos, pues se dieron declaraciones de personalidades políticas, religiosas y de otro tipo, además de concentraciones ciudadanas a favor y en contra de la misma.

Según una encuesta de Ipsos Global Advisor publicada en agosto de 2020 y realizada en 25 países sobre si la población es favorable al aborto legal, Perú se ubica en el puesto 23. Por tanto, la población peruana es de las menos partidarias a la legalización del aborto de los 25 países en que se realizó la encuesta, entre los que se encuentran estados europeos, americanos y asiáticos. Los resultados indican que el $48 \%$ de los peruanos se muestra a favor de la legalización del aborto; y el $40 \%$, en contra. El 12\% restante no sabe o prefiere no responder. Del $48 \%$ a favor de la legalización del aborto, el $32 \%$ considera que solo debe autorizarse en ciertas circunstancias -por ejemplo, cuando una mujer es violada-; mientras que el $16 \%$ opina que el aborto debe permitirse en todos los casos en que una mujer quiera hacerlo. Del $40 \%$ de los peruanos que se oponen a la legalización del aborto, un $28 \%$ opina que este no debe permitirse bajo ninguna circunstancia, excepto cuando la vida de la madre corre peligro; y un 12\% considera que no debe permitirse nunca. Según Ipsos Global Advisor ${ }^{4}$, estos porcentajes se han mantenido estables en el Perú durante los últimos años (Ipsos Global Advisor, 17 de agosto de 2020).

\footnotetext{
${ }^{2}$ Artículo 119 del Código Penal Peruano.

${ }^{3}$ Artículo 120 del Código Penal Peruano.

${ }^{4}$ Para realizar su encuesta, Ipsos entrevistó a un total de 17.997 adultos entre 18 y 74 años en Estados Unidos, Canadá, Malasia, Sudáfrica y Turquía, y entre 16 y 74 en otros 20 países en su plataforma de encuesta en línea Global Advisor entre el 22 de mayo y el 5 de junio de 2020. La muestra consta de aproximadamente 1.000 entrevistados en cada uno de estos países: Australia, Brasil, Canadá, Francia, Alemania, Gran Bretaña, Italia, Japón, España y los Estados Unidos; y 500 entrevistados en: Argentina, Bélgica, Chile, Hungría, India, Malasia, México, Países Bajos, Perú, Polonia, Rusia, Sudáfrica, Corea del Sur, Suecia y Turquía. Las muestras en Brasil, Chile, India, Malasia, México, Perú, Rusia, Sudáfrica y Turquía son más urbanas, más educadas y/o más ricas que la población general. Según Ipsos, los resultados de la encuesta para estos países -entre los que está Perú- deben considerarse como un reflejo de las opiniones del segmento con mayor conexión digital.
} 


\section{Marco teórico}

La producción científica sobre framing es abundante en universidades y centros de investigación académica de todo el mundo. Solo en Hispanoamérica, se han publicado 104 artículos académicos relacionados con el framing durante el periodo 2007- 2016 en las principales revistas Scopus de la región (Piñeiro-Naval y Mangana, 2019, p. 135).

Conviene recordar que existe relación entre los conceptos de framing y agenda-setting. Los medios de comunicación, a la hora de informar sobre la actualidad, tienden a centrarse en determinadas cuestiones en detrimento de otras. McCombs y Shaw (1972) señalan que, mediante la selección de temas, los medios determinan las cuestiones sobre las que el público piensa y habla, y denominan a este proceso con el término agenda-setting (pp.176-187). McCombs (1996) sostiene que el análisis de los encuadres noticiosos (framing) y sus efectos constituye el segundo nivel de la agenda-setting (p. 17). Otros autores como Price, Tewksbury y Powers (1997) diferencian con claridad ambas teorías, pues la agenda-setting se centra en el estudio de los temas que los medios de comunicación consideran de interés periodístico; mientras que el framing se centra en la manera concreta en que los medios de comunicación presentan dichos temas (p. 482). En la actualidad, "existe una corriente mayoritaria entre los investigadores en comunicación que considera que las dos teorías -Framing y Agenda-setting- son complementarias pero autónomas" (Ardèvol-Abreu, 2015, p. 427).

De cualquier modo, los medios de comunicación son intermediarios entre lo que ocurre en el mundo y los ciudadanos. Al informar o al opinar sobre hechos ocurridos, los medios aportan encuadres, enfoques, marcos periodísticos. La realidad que llega al público a través de los periódicos, cadenas de radio o canales de televisión ha atravesado por el "filtro" del medio de comunicación y del profesional que ha elaborado el texto periodístico.

Los autores Igartua y Humanes (2004) explican que

...una información no es un conjunto aleatorio de hechos, sino que más bien se debería hablar de historias informativas que poseen un tema organizador que encuadra los hechos. Así, cuando se alude al concepto de encuadre noticioso (news frame) se está haciendo referencia a la manera en que el comunicador enfoca un tema, fija una agenda de atributos y utiliza un ángulo determinado. Los encuadres, los enfoques, los marcos, permiten al periodista encargarse de grandes cantidades de información de una manera rápida y rutinaria, y envasarla para el consumo público. (p. 256)

Gamson (1989) define news frame como "idea central organizadora que da sentido a los acontecimientos y sugiere cuál es la cuestión tratada" (p.157). Este autor también señala que cuando se analizan las noticias a través de sus encuadres, se busca la intención del emisor del mensaje.

Teóricos de la mediación como Shoemaker y Reese (1996) han distinguido una serie de capas que moldean el contenido periodístico: los factores individuales de cada periodista, las rutinas del trabajo periodístico, los elementos organizativos internos del medio, los factores externos al medio y los elementos ideológicos.

El periodista, cuando se acerca a la realidad y luego informa sobre ella, está condicionado por una serie de ideas, opiniones y experiencias personales y profesionales. En una investigación realizada con 120 periodistas latinoamericanos, uno de los profesionales de la información señalaba: "Definitivamente, la opinión que yo tenga de un tema influye en todo el trabajo, en el eje e incluso en las fuentes que se consultan" (Odriozola-Chéné, Gutiérrez-Atala, Domínguez-Panamá y Pérez-Arozamena, 2019, p. 126).

Académicos como Galdón (2019) consideran que todo texto periodístico -ya sea una noticia, un reportaje, una columna de opinión o un editorial- "implica necesariamente una valoración subjetiva" y "toda información implica una interpretación y una explicación"; al tiempo que considera que "el 
Periodismo debe ser intencional y comprometido según diversos grados, dependiendo de la entidad y trascendencia del tema tratado" (pp. 277-278).

El medio como organización es otro de los niveles de la mediación periodística. Su línea editorial, su estructura interna y sus objetivos empresariales influyen en los mensajes que difunde y en los enfoques que utiliza. Scheufele y Tewksbury (2007) describen los encuadres empleados por los medios como macroconstructos, los cuales resultan útiles para reducir la complejidad de los asuntos y adaptarla a las necesidades de los públicos y los límites de los propios medios. Ya en la mente de los individuos, los encuadres son microconstructos que les permiten emplear la información recibida para formar sus propias ideas y opiniones.

Algunos factores externos que influyen en la elaboración de textos periodísticos son: los contenidos que publican otros medios de comunicación, los intereses de los anunciantes, la cultura dominante en el país o región donde el medio tiene su sede, las opiniones de los líderes sociales y la legislación sobre los medios del país en el que se trabaja. Los encuadres utilizados por actores sociales relevantes están presentes en el debate cuanto más se enfatizan en los medios y más prominente es el orador (Hänggli, 2020).

Por otra parte, los estudiosos del framing distinguen entre encuadres genéricos y específicos. Los encuadres genéricos pueden aplicarse a cuestiones diferentes, a lo largo del tiempo y en diferentes contextos culturales (Vreese, Peter y Semetko, 2001, p. 109). A modo de ejemplo, una clasificación de encuadres genéricos sería aquella que distingue entre una postura a favor, en contra o neutra/ambigua respecto a un asunto determinado (Sádaba, 2007, p. 101). En el caso del presente estudio, se han utilizado este tipo de encuadres genéricos referidos al tema del aborto. Por contraste, los marcos específicos pertenecen a temas o eventos concretos, o hacen referencia a aspectos determinados de un asunto, organización o persona: "Sólo sirven para determinado tema, contexto y lugar" (Sádaba, 2007, p. 100).

\section{Metodología}

Según algunos autores, como Ardèvol-Abreu (2015) e Igartua y Humanes (2004), existen dos formas de abordar el análisis y la medición de los encuadres periodísticos: mediante una aproximación deductiva, se definen teóricamente ciertos encuadres como variables de análisis, y después se verifica su existencia y su frecuencia en los textos periodísticos. La otra forma de análisis de los encuadres es de tipo inductivo, de modo que pueda aparecer un número ilimitado de encuadres posibles.

La presente investigación se ha realizado mediante una aproximación deductiva: se han definido una serie de encuadres, temas y argumentos posibles como categorías del análisis de contenido, y se ha verificado su presencia o ausencia en los textos, así como el grado de frecuencia con que se dan.

En un análisis de contenido se puede distinguir entre variables manifiestas y latentes. Las primeras se refieren a elementos presentes en los mensajes; mientras que las variables latentes "deben ser inferidos a partir de uno o más indicadores manifiestos" (Igartua, 2006, p.185). Para detectar qué encuadres, temas y argumentos están presentes en los textos periodísticos, se han analizado todos los elementos de cada uno de ellos: titulares, subtítulos, sumarios, imágenes, pies de foto, cuerpo de cada texto y fuentes utilizadas.

Los periódicos seleccionados para la investigación son los diarios impresos El Comercio, Perú 21, La República, La Hora, El Tiempo y Correo. Los seis diarios se encuentran entre los periódicos más leídos en Lima metropolitana -El Comercio, Perú 21, La República- y en la región de Piura -La Hora, Correo y El Tiempo-(CPI, marzo 2017). Estos seis diarios poseen una trayectoria histórica y una influencia destacable en el Perú, en las dos zonas geográficas más pobladas del país (INEI, 
2020). Asimismo, estos periódicos difieren entre sí en su línea editorial, tipo de prensa, audiencia y área geográfica de influencia, por lo que la investigación abarca perspectivas diferentes.

Fundado en 1839, El Comercio es uno de los periódicos más antiguos del Perú; tiene una línea editorial liberal, de centro-derecha en lo económico. Perú 21 es un diario de prensa popular ${ }^{5}$, caracterizado por sus portadas sensacionalistas, con una ideología política de centro-derecha. La República es un periódico de ideología política de centro-izquierda. La Hora es también un diario de prensa popular, el más leído en Piura. Correo es un diario de tinte sensacionalista, con diversas ediciones en el país, una de las cuales es la de Piura, sin una tendencia política determinada. En esta investigación, se ha utilizado la edición piurana de Correo. Finalmente, El Tiempo es un periódico de Piura, conservador en lo político y lo económico, y uno de los más influyentes de la región piurana.

Los periódicos impresos siguen siendo relevantes en el Perú. Según un estudio elaborado por Grupo El Comercio en octubre de 2014 -unos meses antes de iniciar nuestra investigación-, los peruanos se encuentran entre aquellos que más leen diarios impresos en el mundo, después de los irlandeses. En Lima, por ejemplo, los periódicos impresos alcanzaban en aquel momento al 89\% de la población de hombres y mujeres de 18 a 65 años, pertenecientes a los sectores socio-económicos $\mathrm{A}, \mathrm{B}$ y $\mathrm{C}$.

Aunque la sociedad se encuentra en pleno auge de los medios digitales, la prensa escrita sigue siendo determinante en el establecimiento de la agenda pública. Si bien existe una crisis de los medios tradicionales, tal y como señalan Suenzo, Boczkowski y Mitchelstein (2021), esta se debe principalmente al problema de la estructura interna y modelo de negocio, pero no a la influencia que aún tienen en la sociedad. En lo que respecta a la investigación de análisis de contenido, encontramos interesantes casos, como el de Asensio y Carmona (2020) y el de Castillo (2020), donde el análisis corresponde a lo publicado en prensa escrita.

Los seis diarios analizados se reciben por suscripción en el Centro de Investigación en Opinión Pública (CIOP) de la Universidad de Piura. Los investigadores de dicha universidad tienen acceso a los ejemplares impresos de El Comercio, La República, Perú 21, Correo, La Hora y El Tiempo, que, como se ha dicho anteriormente, son medios de comunicación relevantes y con altos índices de lectoría en las regiones de Lima metropolitana y Piura. El acceso a los diarios facilitó a los autores realizar la búsqueda, lectura y análisis de los textos que tienen relación con el objeto de estudio.

El presente estudio incluye todos los textos periodísticos cuyo tema principal fue el aborto, publicados por los seis diarios durante los años 2015, 2016, 2017, 2018 y 2019. Al inicio de este periodo de tiempo, tal y como se explicó en la Introducción, se presentó una iniciativa legislativa -promovida por cuarenta organizaciones civiles peruanas- que buscaba despenalizar el aborto en el Perú en determinados casos. El proyecto de ley fue archivado por la Comisión de Justicia y Derechos Humanos del Congreso a finales de 2015. Ya en 2016, la Comisión de Constitución del Congreso rechazó reconsiderar el proyecto legislativo. Se ha querido extender el periodo de análisis, para tener una perspectiva más amplia sobre el tratamiento de la cuestión del aborto en los medios. En los cinco años abarcados por el estudio, se han publicado 160 textos. Todos ellos han sido analizados para realizar esta investigación (ver tabla 1). Los resultados de esta investigación se presentan en porcentajes, redondeados a su parte entera.

\footnotetext{
${ }^{5}$ La Fundación Gabo define prensa popular como aquella que "se ocupa en primer lugar de comunicar las noticias de mayor impacto y la relación con la vida de la población y que, en segundo lugar, se vale de técnicas de comunicación, entre otras, el lenguaje sencillo y amigable que les permite a las clases populares acceder al conocimiento de la realidad".
} 
Tabla 1. Número de textos periodísticos por diario

\begin{tabular}{|l|l|}
\hline Diario & Cantidad \\
\hline La República & 35 \\
\hline El Comercio & 34 \\
\hline Correo & 29 \\
\hline Perú 21 & 22 \\
\hline El Tiempo & 21 \\
\hline La Hora & 19 \\
\hline Total & 160 \\
\hline
\end{tabular}

Fuente: Centro de Investigación en Opinión Pública (CIOP). Universidad de Piura

El análisis de contenido aplicado a los 160 textos ha incluido variables formales y variables de contenido. Respecto a las variables formales, se han tenido en cuenta la fecha de publicación; el género periodístico utilizado - columna de opinión, crónica, editorial, entrevista, noticia, reportaje, perfil u otro-; y la sección en la que fue publicado el texto: noticia principal (Portada), Opinión, Política, Nacional, Local/Regional, Internacional, Policial, Economía, Farándula, Ciencia y Tecnología, y Otra sección.

En cuanto a las variables de contenido, se ha establecido una primera sobre los encuadres genéricos predominantes en los textos. En esta variable, se han fijado tres categorías posibles: encuadre provida $^{6}$, cuando el texto en su conjunto y/o la fuente principal proyectan una postura en defensa del concebido o contraria al aborto; encuadre proaborto ${ }^{7}$, cuando la fuente principal y/o el texto en su conjunto manifiestan una posición favorable al aborto; y encuadre neutro o ambiguo es aquel en el que no se destacan elementos a favor o en contra del aborto.

La segunda variable del análisis de contenido ha tenido el propósito de averiguar los temas principales sobre los que giraba cada texto. Después de un primer análisis exploratorio, las categorías que se establecieron son: "Despenalización del aborto"; "Concentraciones ciudadanas (en contra o a favor del aborto)"; "Casos y tipos de aborto"; "Creencias religiosas"; "Contraceptivos/madres solteras"; "Penalización del aborto clandestino"; "Causas y consecuencias del aborto"; "Moral"; y "Otros".

La tercera variable del análisis de contenido ha tenido como finalidad detectar el "Motivo principal por el que se rechaza el aborto". Tras una exploración preliminar, los argumentos en contra del aborto detectados fueron: "Porque se debe respetar el derecho a la vida desde la concepción"; "Porque los traumas psicológicos del embarazo pueden superarse"; "Porque moralmente está mal"; "Por creencia religiosa"; "Porque la ley lo prohíbe"; "Más de un argumento"; "Otro motivo". La categoría "No aplica" de esta variable se diseñó para los textos en los que no se hallaron argumentos a favor del aborto.

La cuarta variable del análisis de contenido se estableció para detectar el "Motivo principal por el que se apoya el aborto inducido". Los argumentos que se hallaron fueron los siguientes: "Porque la madre no podrá mantener al concebido"; "Porque la mujer tiene derecho a decidir libremente"; "Porque el embarazo es producto de una violación"; "Porque el feto tiene malformaciones"; "Por-

\footnotetext{
${ }^{6}$ El Diccionario de la Real Academia Española define "provida" del siguiente modo: "Que se opone al aborto inducido, a la investigación con embriones humanos y a la eutanasia".

7 El Diccionario de la Real Academia Española define "pro" como "en favor de", "partidario de". Hemos optado por usar el término "proaborto" en lugar de "abortista", dado que el Diccionario de la Real Academia Española define "abortista" como "partidario de la práctica libre del aborto provocado", y existen personas partidarias del aborto solo para determinados casos.
} 
que la gestación pone a la madre en peligro de muerte o de un mal grave permanente"; "Más de un argumento"; "Otro motivo". La categoría "No aplica" de esta variable se diseñó para los textos en los que no se encontraron argumentos en contra del aborto.

Para estas dos variables de contenido - tercera y cuarta- se diseñaron categorías analizables por separado. Esto, no solo con la finalidad de facilitar el levantamiento de la información, sino porque en el testeo previo al diseño de la ficha de análisis de contenido, se identificó que los motivos a favor y en contra se mueven en líneas argumentales distintas.

Finalmente, se estableció una variable del análisis de contenido para identificar las fuentes principales presentes en los textos, a las que acudieron los periodistas para redactarlos. Estas influyen en el establecimiento de un encuadre $u$ otro, de un punto de vista $u$ otro, de un enfoque $u$ otro para definir los hechos y situaciones. Las fuentes han sido agrupadas por los ámbitos a los que pertenecen, en las siguientes categorías: "Experto (técnico/científico)", "Político", "Cultural", "Religioso", "Periodístico", "Farandulero" y "Otros". En los casos en que no se ha identificado una fuente principal en el texto, la categoría utilizada ha sido "No aplica".

En la tabla 2 se presentan todas las variables y categorías de la investigación.

Tabla 2. Ficha de análisis de contenido

\begin{tabular}{|c|c|}
\hline Variables formales & Categorías formales \\
\hline 1. Año de publicación & $A=2015 . B=2016 . C=2017 . D=2018 . E=2019$. \\
\hline 2. Género periodístico & $\begin{array}{l}1=\text { Columna de opinión. } 2=\text { Crónica. } 3=\text { Editorial } . \\
4=\text { Entrevista } .5=\text { Noticia. } 6=\text { Reportaje. } 7=\text { Otro. }\end{array}$ \\
\hline $\begin{array}{l}\text { 3. Sección en la que fue } \\
\text { publicado el texto }\end{array}$ & $\begin{array}{l}1=\text { Noticia principal }(\text { Portada). } 2=\text { Opinión. } \\
3=\text { Política. } 4=\text { Nacional. } 5=\text { Local } / \text { Regional } . \\
6=\text { Internacional. } 7=\text { Policial. } 8=\text { Economía } . \\
9=\text { Farándula } .10=\text { Ciencia y Tecnología. } 11=\text { Otra } .\end{array}$ \\
\hline Variables de contenido & Categorías de contenido \\
\hline $\begin{array}{l}\text { 1. Encuadre genérico } \\
\text { predominante en el texto }\end{array}$ & 1= Provida. 2 = Proaborto. 3 = Neutro/ambiguo. \\
\hline $\begin{array}{l}\text { 2. Tema predominante sobre } \\
\text { el que gira el texto }\end{array}$ & $\begin{array}{l}1 \text { = Despenalización del aborto. } 2=\text { Concentraciones ciudadanas (en contra o } \\
\text { a favor del aborto). } 3=\text { Casos y tipos de aborto. } 4=\text { Creencias religiosas. } \\
5=\text { Contraceptivos/madres solteras. } 6=\text { Penalización del aborto clandestino. } 7 \\
=\text { Causas y consecuencias del aborto. } 8=\text { Moral. } 9=\text { Otros. }\end{array}$ \\
\hline $\begin{array}{l}\text { 3. Motivo principal por el que } \\
\text { se rechaza el aborto }\end{array}$ & $\begin{array}{l}1=\text { Porque se debe respetar el derecho a la vida desde la concepción. } 2= \\
\text { Porque los traumas psicológicos del embarazo pueden superarse. } 3=\text { Porque } \\
\text { moralmente está mal. } 4=\text { Por creencia religiosa. } 5=\text { Porque la ley lo prohíbe. } 6 \\
=\text { Más de un argumento. } 7 \text { = Otro motivo. } \\
8=\text { No aplica. }\end{array}$ \\
\hline $\begin{array}{l}\text { 4. Motivo principal por el que } \\
\text { se apoya el aborto inducido }\end{array}$ & $\begin{array}{l}1=\text { Porque la madre no podrá mantener al concebido. } \\
2=\text { Porque la mujer tiene derecho a decidir libremente. } \\
3=\text { Porque el embarazo es producto de una violación. } \\
4=\text { Porque el feto tiene malformaciones. } 5 \text { = Porque la gestación pone a la } \\
\text { madre en peligro de muerte o de un mal grave permanente. } 6 \text { = Más de un } \\
\text { argumento. } \\
7=\text { Otro motivo. } 8 \text { = No aplica. }\end{array}$ \\
\hline $\begin{array}{l}\text { 5. Ámbito al que pertenece la } \\
\text { fuente principal del texto }\end{array}$ & $\begin{array}{l}1=\text { Experto (técnico/científico). } 2=\text { Político. } \\
3=\text { Cultural. } 4=\text { Religioso. } 5=\text { Periodístico. } \\
6=\text { Farandulero. } 7=\text { Otros. } 8=\text { No aplica }\end{array}$ \\
\hline
\end{tabular}

Fuente: Centro de Investigación en Opinión Pública (CIOP). Universidad de Piura 
La portada de un diario cumple un rol fundamental en la visibilización y compra del periódico. Como señala Pedrazzini (2011), la portada es la vitrina, la carta de presentación del medio. Es la última página que se confecciona antes de imprimir el diario, cuando ya se tiene una panorámica global de las noticias del día, y se confecciona mediante un proceso de selección de los temas y encuadres que más se ajustan a la línea editorial y los criterios periodísticos de los responsables del diario.

A modo de muestra representativa, se ha realizado un segundo análisis de contenido de carácter cualitativo, centrado en los diez textos que aparecieron publicados como noticia principal (portada) de los diarios seleccionados. En dicho análisis, se presenta una descripción del titular, el subtítulo, los sumarios, las fotografías y los pies de foto de cada texto, junto al encuadre predominante y la fuente principal utilizada en cada uno de ellos.

\section{Resultados}

De los seis diarios analizados, La República y El Comercio fueron los periódicos que más atención prestaron al tema del aborto durante los años 2015 a 2019: el 22\% y el 21\% respectivamente del total de textos analizados fueron publicados por dichos diarios. Por contraste, los diarios La Hora y El Tiempo dedicaron menos espacio a la cuestión del aborto en sus páginas: $12 \%$ y $13 \%$ de los textos analizados. Correo y Perú 21 completan los demás textos analizados, con el 18\% y 14\% respectivamente del conjunto de textos periodísticos (ver tabla 3 ).

Tabla 3. Porcentaje de cada diario sobre el total de textos publicados

\begin{tabular}{|l|c|}
\hline Diario & $\%$ \\
\hline La República & $22 \%$ \\
\hline El Comercio & $21 \%$ \\
\hline Correo & $18 \%$ \\
\hline Perú 21 & $14 \%$ \\
\hline El Tiempo & $13 \%$ \\
\hline La Hora & $12 \%$ \\
\hline Total & $100 \%$ \\
\hline
\end{tabular}

Fuente: Centro de Investigación en Opinión Pública (CIOP).Universidad de Piura

En todos los diarios, se observa que los años 2015 y 2016 fueron en los que más textos sobre el aborto se publicaron: 52 y 81 respectivamente. Este hecho coincide con la tramitación en el Congreso de la República de un proyecto de ley que, como se ha mencionado en la introducción, buscaba despenalizar el aborto en los casos de embarazo a consecuencia de violación sexual, inseminación artificial o transferencia de óvulos no consentidos. En 2017, se publicaron diez textos periodísticos sobre el tema del aborto en los periódicos analizados; quince textos en 2018; y solo tres en 2019.

Las secciones en las que fueron publicados más textos sobre la cuestión del aborto fueron: Nacional (17\% del total) y Local/Regional (también 17\%). Asimismo, los diarios se sirvieron de las secciones de Política e Internacional (14\% cada una) para publicar sus textos sobre el aborto. Como se aprecia, la cuestión del aborto fue considerada como un tema que tiene relación con diversos ámbitos geográficos, además de ser un tema con connotaciones políticas. En la sección de Opinión fueron publicados el 11\% de los textos analizados. El 6\% de los textos periodísticos -que son diez- aparecieron como Noticia principal (Portada); el 1\% fueron publicadas en la sección de Farándula; otro 1\%, en la sección Ciencia y Tecnología; y el 19\% restante, en otras secciones. 
El género periodístico más utilizado para hablar sobre el aborto fue la noticia: un $62 \%$ de los textos fueron noticias. El 14\% de los textos fueron crónicas. El 13\% fueron columnas de opinión. Entrevistas $(6 \%)$, reportajes $(2 \%)$, otros géneros $(2 \%)$ y editoriales $(1 \%)$ fueron los géneros periodísticos restantes de los textos analizados.

Respecto a los encuadres genéricos detectados, los resultados unificados de los seis diarios reflejan que el $42 \%$ de los textos publicados tuvieron un encuadre provida; el $28 \%$ utilizaron un marco proaborto; y el 30\% restante, un encuadre neutro o ambiguo.

Si se distinguen estos resultados por periódicos, se aprecian diferencias relevantes: Correo, $\mathrm{La}$ Hora y El Tiempo fueron los diarios que publicaron más textos con un encuadre provida: el 59\%, $47 \%$ y $44 \%$ respectivamente. Estos tres diarios utilizaron un marco proaborto en el $18 \%, 21 \%$ y $28 \%$ respectivamente de los textos periodísticos que publicaron. El resto de los textos tuvieron un marco neutro o ambiguo (Correo, 23\%; La Hora, 32\%; y El Tiempo, 28\%).

También los diarios Perú 21 y La República utilizaron un marco provida en el 43\% y el 39\% de sus textos respectivamente, y un encuadre proaborto en el $19 \%$ y $25 \%$ de los textos respectivamente. El $38 \%$ y $36 \%$ de los textos restantes de Perú 21 y La República tuvieron un encuadre neutro o ambiguo. En contraste con los cinco diarios anteriores, El Comercio fue el único periódico que empleó mayoritariamente un encuadre proaborto; así lo hizo en el $47 \%$ de los textos publicados sobre el tema. El 29\% de sus publicaciones sobre el tema estudiado tuvieron un marco provida; y el 24\%, un encuadre neutro o ambiguo.

A continuación, se muestran estos resultados, distinguiendo entre los diarios que forman parte de la prensa más leída en el área de Lima metropolitana, y entre los periódicos que forman parte de la prensa más leída en la región de Piura (ver figuras 1 y 2).

Figura 1. Encuadres genéricos por diarios (región Lima metropolitana)

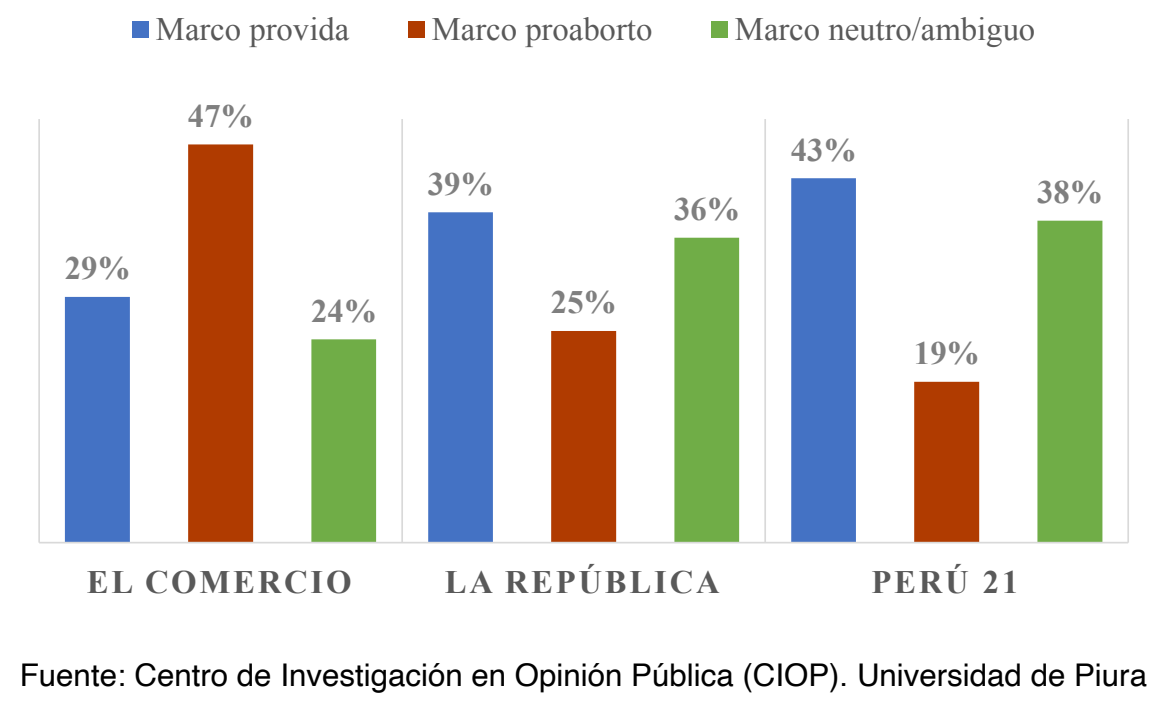


Figura 2. Encuadres genéricos por diarios (región Piura)

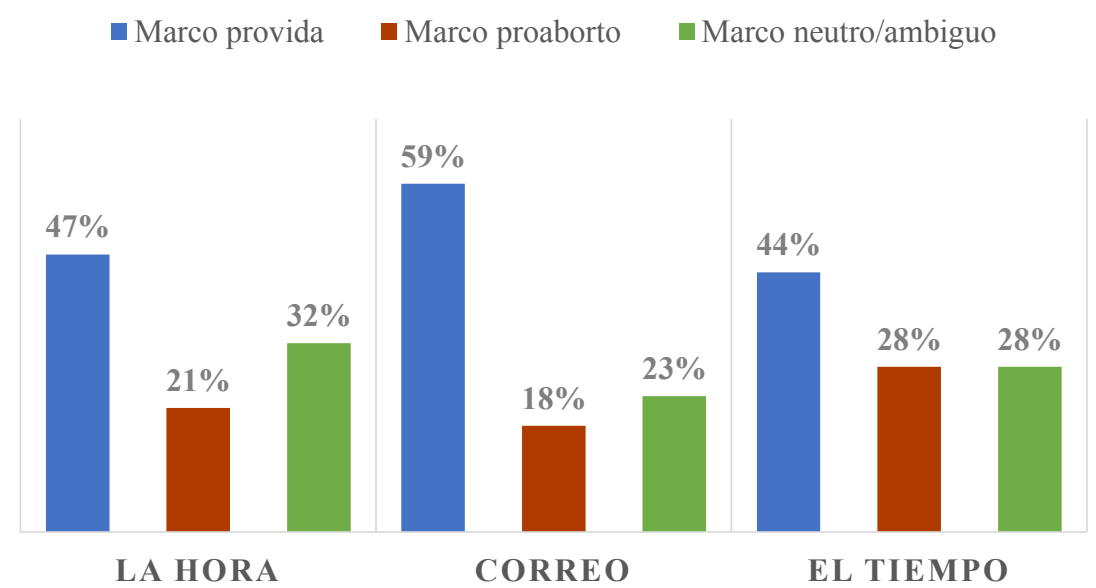

Fuente: Centro de Investigación en Opinión Pública (CIOP). Universidad de Piura

Los resultados diferenciados por áreas geográficas permiten observar que los diarios que forman parte de la prensa más leída en la región de Piura -La Hora, Correo y El Tiempo- utilizaron encuadres más provida que los diarios que forman parte de la prensa más leída en el área de Lima metropolitana -El Comercio, Perú 21 y La República.

En cuanto a la variable acerca de los temas predominantes sobre los que giraron los textos, se observa que la "Despenalización del aborto" es el más recurrente (32\% del total), seguido por el tema "Contraceptivos/madres solteras" (19\%), las "Concentraciones ciudadanas, en contra o a favor del aborto" (12\%) y las "Creencias religiosas" (12\%). En la figura 3, se muestran los resultados completos de este apartado.

Figura 3.Tema predominante sobre el que giraron los textos publicados

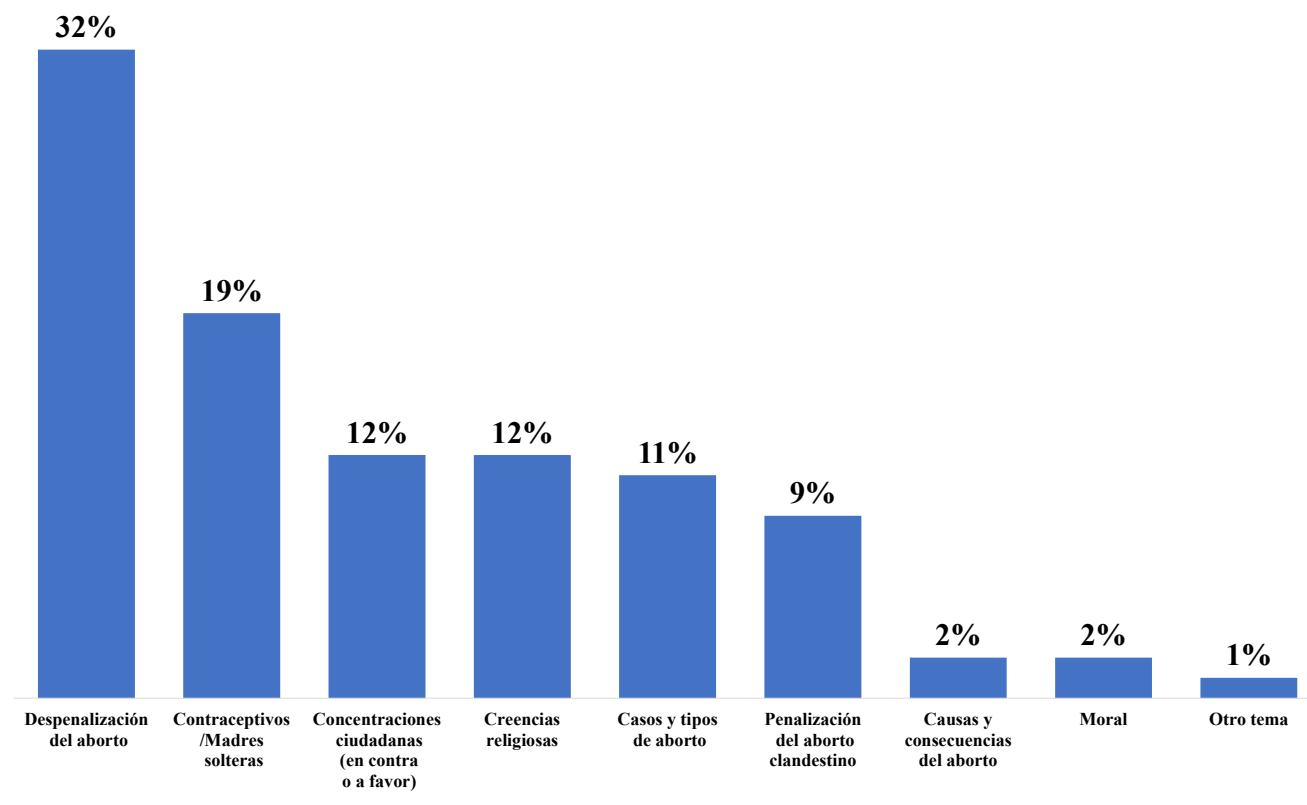

Fuente: Centro de Investigación en Opinión Pública (CIOP). Universidad de Piura 
Respecto a la variable "Motivo principal por el que se rechaza el aborto", en el 16\% de los textos fue "Porque se debe respetar el derecho a la vida desde la concepción". Los motivos "Por creencia religiosa" y "Porque la ley lo prohíbe" estuvieron presentes cada uno de ellos en el $12 \%$ de los textos. La categoría "No aplica" de esta variable se ha utilizado para los textos que no presentan argumentos a favor del aborto. Tal y como se puede ver en la tabla 4.1, hacerlo de este modo permite tener una lectura completa del fenómeno, manteniendo el 100\% de los resultados en sintonía con la totalidad de los textos analizados.

En cuanto a la variable "Motivo principal por el que se apoya el aborto inducido", el 14\% de los textos analizados empleó el argumento "Porque es producto de una violación". Asimismo, el motivo "Porque la mujer tiene derecho a decidir libremente" estuvo presente en el 10\% de los textos periodísticos; y en el 6\% de ellos, se detectaron "Otro motivo" y "Más de un argumento" para apoyar el aborto inducido (ver tablas 4.1 y 4.2). La categoría "No aplica" de esta variable se ha utilizado para los textos que no presentan argumentos en contra del aborto. Tal y como se puede ver en la tabla 4.2, hacerlo de este modo permite tener una lectura completa del fenómeno, manteniendo el 100\% de los resultados en sintonía con la totalidad de los textos analizados.

Tabla 4.1

Motivo principal por el que se rechaza el aborto

\begin{tabular}{|l|r|r|}
\hline Motivo & Textos & \multicolumn{1}{c|}{$\%$} \\
\hline - No aplica & 69 & $43 \%$ \\
\hline $\begin{array}{l}\text { - Porque se debe respetar el } \\
\text { derecho a la vida desde la con- } \\
\text { cepción }\end{array}$ & 26 & $16 \%$ \\
\hline - Por creencia religiosa & 19 & $12 \%$ \\
\hline - Porque la ley lo prohíbe & 19 & $12 \%$ \\
\hline - Más de un argumento & 15 & $9 \%$ \\
\hline - Otro motivo & 8 & $5 \%$ \\
\hline - Porque moralmente está mal & 3 & $2 \%$ \\
\hline $\begin{array}{l}\text { - Porque los traumas psicológi- } \\
\text { cos pueden superarse }\end{array}$ & 1 & $1 \%$ \\
\hline & 160 & $100 \%$ \\
\hline
\end{tabular}

Tabla 4.2

Motivo principal por el que se apoya el aborto inducido

\begin{tabular}{|c|c|c|}
\hline Motivo & Textos & $\%$ \\
\hline - No aplica & 96 & $60 \%$ \\
\hline - Porque es producto de una violación & 23 & $14 \%$ \\
\hline $\begin{array}{l}\text { - Porque la mujer tiene derecho a } \\
\text { decidir libremente }\end{array}$ & 16 & $10 \%$ \\
\hline - Otro motivo & 10 & $6 \%$ \\
\hline - Más de un argumento & 10 & $6 \%$ \\
\hline $\begin{array}{l}\text { - Porque pone a la madre en peligro } \\
\text { de muerte o de un mal grave } \\
\text { permanente }\end{array}$ & 3 & $2 \%$ \\
\hline $\begin{array}{l}\text { - Porque la madre no podrá } \\
\text { sostenerlo }\end{array}$ & 1 & $1 \%$ \\
\hline \multirow[t]{2}{*}{ - Porque el feto tiene malformaciones } & 1 & $1 \%$ \\
\hline & 160 & $100 \%$ \\
\hline
\end{tabular}

Fuente: Centro de Investigación en Opinión Pública (CIOP). Universidad de Piura

La fuente principal utilizada por los diarios pertenece al ámbito político en un $23 \%$ de los textos analizados. Las fuentes pertenecientes al ámbito religioso son las principales en el $21 \%$ de los textos. Los expertos técnicos o científicos son la fuente principal en el $16 \%$ de los textos; y el ciudadano común está presente como fuente principal en el 16\% de los textos (ver figura 4).

Se presentan ahora los resultados del segundo análisis de contenido, de tipo cualitativo, aplicado a los textos periodísticos publicados como noticia principal (Portada). Estos fueron publicados por Correo (tres textos), El Comercio (dos textos), Perú 21 (dos textos), La República (dos textos) y El Tiempo (un texto). Los encuadres predominantes de dichos textos fueron: provida (tres textos), proaborto (dos textos) y neutro/ambiguo (cinco textos). 
Figura 4. Ámbito al que pertenece la fuente principal del texto periodístico

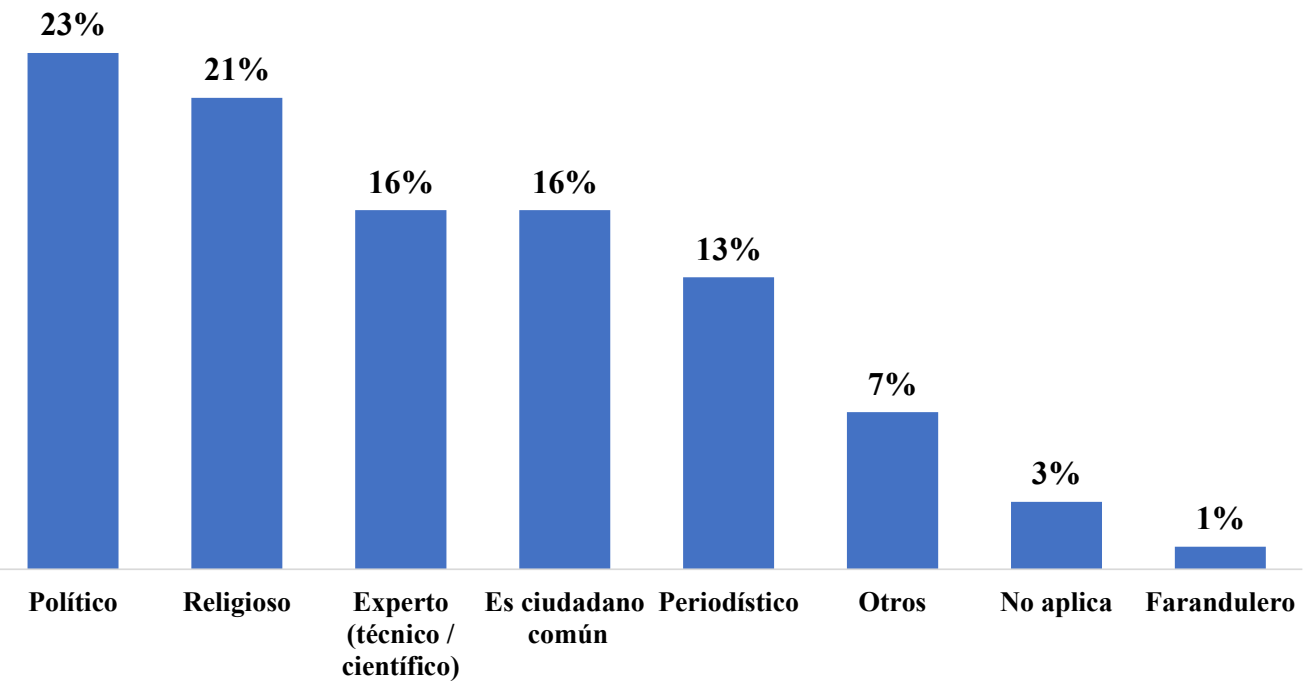

Fuente: Centro de Investigación en Opinión Pública (CIOP). Universidad de Piura

Si se comparan los resultados de los textos que aparecieron como portada y los resultados globales de todos los textos, se aprecia un menor porcentaje de textos con un encuadre provida (tres de diez, frente al $42 \%$ de todos los textos en su conjunto), y de textos en portada con un marco proaborto (dos de diez, frente al $28 \%$ de todos los textos). En cambio, se observa un porcentaje mayor de textos en portada con un encuadre neutro o ambiguo (cinco de diez, frente al 30\% de todos los textos).

La fuente principal de los textos que fueron noticia principal (Portada) pertenece al ámbito político: seis de diez. De estas, cuatro tuvieron un encuadre neutro/ambiguo, dos fueron proaborto, y ninguno provida. Por contraste, los dos textos que fueron portada y su fuente principal pertenece al ámbito religioso, tuvieron un encuadre provida, lo cual se corresponde con la posición de la Iglesia católica y de otras confesiones cristianas, presentes en la cultura y en la vida de los peruanos. Según el informe titulado "Perú: Perfil Sociodemográfico", publicado en septiembre de 2018 por el INEI, del total de la población de doce y más años de edad, el 76\% de los peruanos profesan la religión católica, el 14,1\% son cristianos evangélicos, el 4,8\% cree en otra religión; y el 5,1\% no tiene ninguna religión.

Tabla 5. Resultados de los textos que fueron noticia principal (Portada)

\begin{tabular}{|c|c|c|c|c|}
\hline $\begin{array}{l}\text { Año de } \\
\text { publicación }\end{array}$ & $\begin{array}{l}\text { Día de publicación- } \\
\text { Mes }\end{array}$ & Diario & Encuadre genérico & $\begin{array}{l}\text { Ámbito de la fuente } \\
\text { principal }\end{array}$ \\
\hline \multirow{3}{*}{2015} & 12-junio & El Comercio & Neutro/ambiguo & Experto técnico/científico \\
\hline & 31-agosto & Perú 21 & Proaborto & Político \\
\hline & 25-noviembre & El Comercio & Proaborto & Político \\
\hline \multirow{6}{*}{2016} & 28-marzo & Correo & Neutro/ambiguo & Político \\
\hline & 31-marzo & El Tiempo & Provida & Religioso \\
\hline & 4-mayo & La República & Neutro/ambiguo & Político \\
\hline & 16-agosto & Correo & Provida & Otros \\
\hline & 24-agosto & La República & Neutro/ambiguo & Político \\
\hline & 24-agosto & Perú 21 & Neutro/ambiguo & Político \\
\hline 2018 & 6-mayo & Correo & Provida & Religioso \\
\hline
\end{tabular}

Fuente: elaboración propia. 
Finalmente, presentamos una breve descripción de los principales elementos de los diez textos periodísticos que fueron noticia principal (Portada):

- El Comercio (12/06/2015). Titular de portada: "Eguren y la ciencia de lo imposible”. Subtítulo: "Fertilidad para 'dummies'. Los fundamentos biológicos que cuestionan las polémicas declaraciones del congresista pepecista sobre la violación". En la foto, aparece el congresista Juan Carlos Eguren, del Partido Popular Cristiano. En la página 2, el subtítulo es el siguiente: "Médicos rebaten al legislador pepecista, quien había dicho: es casi imposible que se produzca un embarazo después de una violación".

- Perú 21 (31/8/2015). Información con referencia en portada y que ocupa la página 2, basada en unas declaraciones del presidente de la República, Ollanta Humala, acerca de un posible indulto al expresidente Alberto Fujimori y al militar Antauro Humala. El sumario principal del texto es: "Creo que la mujer debe decidir sobre su cuerpo (sobre la despenalización del aborto)".

- El Comercio (25/11/2015). El titular de portada es: "El aborto por violación seguirá penalizado", junto a una foto de tres mujeres con letreros en los que se lee: "No más muertas por abortos clandestinos". En la página 4, el titular es: "Congreso archiva el predictamen que despenaliza el aborto por violación", junto al siguiente subtítulo: "El proyecto fue rechazado en la Comisión de Constitución con los votos de legisladores de Fuerza Popular, el Apra y el PPC". En la fotografía que acompaña al texto, aparecen dos congresistas, con el siguiente pie de foto: "Resignados. Fredy Otarola señaló que le resulta curioso que quienes fomentaron las esterilizaciones forzadas ahora hablen de temas morales. Rosa Mavila sostuvo que se mencionaron los derechos del embrión, pero no se dijo nada de los derechos de las mujeres agredidas".

- Correo (28/3/2016). El "Tema del día" (referencia en portada y páginas 2 y 3) tiene como titular principal: "Candidatos hablan sobre el aborto". El subtítulo es: "Muchos de los postulantes no son claros con sus posturas y pocos tienen propuestas alternativas". En el texto, se ofrecen declaraciones de seis candidatos piuranos que postulaban en aquel momento al Congreso, con sus posturas sobre el aborto y su despenalización en determinados supuestos. Cada uno de los candidatos representaba a un partido político distinto: Alianza Popular, Perú Posible, Solidaridad Nacional, Alianza para el Progreso, Peruanos por el Kambio y Partido Orden.

- El Tiempo (31/03/2016). El titular de portada es el siguiente: "Monseñor: No voten por los candidatos proaborto", junto a una foto del arzobispo de Piura, monseñor José Antonio Eguren, que ocupa tres cuartas partes de la portada. El subtítulo de portada es el siguiente: "Arzobispo José Eguren se suma a protesta de su homólogo de Arequipa y pide a los votantes católicos rechazar las propuestas del 'matrimonio gay"'. En la página 3, se explica que el arzobispo dio dichas declaraciones al anunciar una marcha por la vida. En la fotografía de la página 3, aparece de nuevo el arzobispo de Piura con un muñequito de un feto humano, y el siguiente pie de foto: "El arzobispo José Eguren Anselmi sostiene que sobre la defensa de la vida y la unidad familiar no se puede negociar". En otra imagen que ilustra la noticia, se puede ver a un grupo de mujeres jóvenes que visten camisetas con el lema: “¡viva mi hijo por nacer!”.

- La República (04/05/2016). Información publicada en la página 2 y con referencia en portada, sobre un evento multitudinario de la comunidad evangélica peruana, en el que participó Keiko Fujimori, candidata presidencial por el partido Fuerza Popular. En dicho evento, la candidata firmó un acta de compromiso en defensa del matrimonio y la vida en todas sus 
etapas, rechazando la unión civil y el matrimonio entre personas del mismo sexo, así como toda práctica abortiva. En las fotos, tomadas durante el evento, aparecen Keiko Fujimori y el pastor evangélico promotor de la citada acta.

- Correo (16/08/2016). El "Tema del día" (referencia en portada y páginas 2 y 3 ) tiene como titular principal: "Pastillas para abortar y 'pepear' se venden como si fueran caramelos de limón"; y como subtítulo: "Fármacos que se deberían ofrecer solo bajo prescripción médica se venden de manera indiscriminada". En el texto, se explica que un redactor del periódico pudo comprar sin receta "el abortivo Cycotec en una tienda del sector Herbolarios del Mercado de Piura y el sedante Alprazolan en una botica formal". 'Pepear' es un término de la jerga peruana que significa adormecer a una persona por medio de sustancias introducidas en sus bebidas.

- La República (24/08/2016). El titular de la información, publicada en página 2, es el siguiente: "Minsa [Ministerio de Salud] acatará fallo y entregará gratis la píldora del día siguiente". El subtítulo del texto es: "Patricia García, ministra de Salud, anunció que se están elaborando las guías técnicas y que se capacitará al personal médico para iniciar su distribución”. Se refiere a un fallo judicial, dictado por el Primer Juzgado Constitucional de Lima, que obligaba a restablecer la distribución gratuita de dicha píldora. En la página 3, aparece una infografía titulada: "Anticonceptivo oral de emergencia, ¿qué dice la OMS?" En ella se afirma que esta píldora "no provoca aborto", según la Organización Mundial de la Salud. En el texto de la noticia, también aparecen declaraciones del presidente de la Conferencia Episcopal Peruana, monseñor Salvador Piñeiro, señalando que dicha píldora produce un "microaborto".

- Perú 21 (24/08/2016). Esta información ocupa las páginas 2 y 3, y el titular principal es el siguiente: "Gobierno acatará distribución de píldora". El antetítulo es: "Ministerio de Salud prepara logística y personal para distribuir, de manera adecuada, el anticonceptivo oral de emergencia, tal como lo ha dispuesto el Primer Juzgado Especializado Constitucional de Lima”. El texto de la noticia viene acompañado por una infografía sobre el funcionamiento de dicha píldora. Asimismo, la información incluye declaraciones a favor y en contra de dicho producto, por no considerarlo o por considerarlo abortivo.

- Correo (06/05/2018). El titular de portada es: "Muestran su rechazo al aborto", junto al subtítulo "Miles de piuranos salen a las calles para participar de la Marcha por la Vida". En la foto de portada, aparece la cabecera de la marcha, con el lema: "Piura celebra y defiende la vida y la familia". En la página 5, el titular es: "Miles de piuranos salieron a las calles a defender la vida desde la concepción", junto al subtítulo "Instituciones públicas, privadas y religiosas participaron del I Corso y el X Festival por la vida”. Según se lee en el texto, el principal promotor de la iniciativa fue el arzobispo de Piura, monseñor José Antonio Eguren, quien fue una de las personas que encabezó la marcha y pronunció unas palabras durante la misma. La fotografía de la página 5 muestra una imagen de la marcha.

\section{Discusión y conclusiones}

El principal objetivo de esta investigación consistía en averiguar qué enfoques utiliza la prensa peruana al abordar el tema del aborto, empleando una ficha de análisis de contenido con los encuadres genéricos provida, proaborto y neutro/ambiguo, profundizando, además, en los motivos que están detrás de estas posturas, y detectando las principales fuentes a las que acuden los periodistas para generar sus contenidos.

Del análisis realizado hay una primera conclusión general: entre los años 2015 y 2019 ha predominado un enfoque provida en la prensa escrita peruana. Si bien se encontraron matices entre los distintos diarios analizados, se observa que los textos con un marco provida han sido el $42 \%$ del 
total, mientras que aquellos con un encuadre proaborto han sido el $28 \%$; y el $30 \%$ restante se ha mantenido en el terreno de lo neutral o ambiguo.

Un segundo análisis llevó a los autores a distinguir la diferencia de resultados entre los textos publicados por la prensa más leída en las regiones de Lima metropolitana y Piura. El resultado general arroja que en Piura los periódicos analizados han destacado por publicar textos con un encuadre más provida: el $50 \%$ de las publicaciones así lo ha mostrado, mientras que el $22 \%$ del contenido analizado ha sido proaborto y el $28 \%$ ha sido neutro/ambiguo. En el caso de los diarios de Lima, el resultado global muestra que el $37 \%$ de los textos publicados han tenido un enfoque provida; el $30 \%$, un encuadre proaborto; y el 33\% fueron neutros o ambiguos.

Si se entra a un análisis pormenorizado por medio de comunicación, se aprecia que cinco de los seis periódicos estudiados -todos excepto El Comercio- han utilizado mayoritariamente un encuadre provida al informar u opinar sobre el aborto. Estos diarios son: Correo, La Hora, El Tiempo, Perú 21 y La República, ordenados según sus encuadres más provida y menos proaborto.

Dentro de este mismo análisis, la investigación encontró una diferencia entre los encuadres de $E l$ Comercio y La República, los medios de circulación nacional con mayor incidencia en la agenda pública peruana. Cuando se realiza la comparación entre estos medios, se evidencia que, en un mismo periodo de tiempo, La República tiene un 39\% de textos provida, mientras que El Comercio un $29 \%$. Si se analizan los contenidos ya manifiestamente a favor del aborto, el resultado evidencia que el $47 \%$ del contenido de El Comercio usa un encuadre proaborto, mientras que en el caso de $L a$ República este porcentaje es del 25\%. Por tanto, la investigación arroja que El Comercio utilizó más veces encuadres proaborto que diario La República.

Finalmente, un tercer ámbito de análisis se encuentra en el tipo de fuente a la que recurren los periodistas para informar sobre el aborto. Como señala Luhmann (2000), las fuentes influyen en el establecimiento de los encuadres periodísticos. Al revisar el tipo de fuente que utiliza el periodista para construir su información, se aprecia que, del total de informaciones publicadas, el 23\% utiliza como fuente a personas o instituciones provenientes del ámbito político; el 21\%, del ámbito religioso; y un 16\% acude a fuentes del ámbito científico.

Queda para futuras investigaciones analizar en profundidad en qué medida los encuadres noticiosos utilizados por los medios impresos peruanos se corresponden con los marcos culturales presentes en el Perú, para estudiar si existe o no un paralelismo entre estos dos aspectos de la teoría del Framing.

\section{Bibliografía}

Ardèvol-Abreu, A. (2015). Framing o teoría del encuadre en comunicación. Orígenes, desarrollo y panorama actual en España. Revista Latina de Comunicación Social, (70), 423-450. https://doi. org/10.4185/RLCS-2015-1053

Asensio, M.; Carmona, J. (2020). Análisis discursivo de la representación en prensa de los refugiados en el ámbito educativo. Tonos digital: Revista de Estudios Filológicos, (38), 1-20. http://hdl.handle.net/10201/86450

Castillo Fernández, A. (2020). La representación mediática de las migraciones en la prensa española durante la pandemia. Revista Andaluza de Antropología, (19), 117-131. https://dx.doi. org/10.12795/RAA.2020.19.07

Congreso de la República (2015). Comisión de justicia y derechos humanos. Período anual de sesiones 2014-2015. Predictamen de la comisión de justicia y derechos humanos. Versión V actualizada al 22 de mayo de 2015. https://bit.ly/3xxRHzr 
Compañía Peruana de Estudios de Mercado y Opinión Pública (CPI) (marzo 2017). Estudio de lectoría de diarios en Lima y 15 principales ciudades.

Grupo El Comercio (octubre 2014). Los medios impresos en la era digital. http://ecomedia.pe/f/ pdf/eradigital.pdf?v255

Entman, R. M. (1993). Framing: Toward Clarification of a Fractured Paradigm. Journal of Communication, 43(4), 51-58. https://doi.org/10.1111/j.1460-2466.1993.tb01304.x

Galdón, G. (2019). Infoética. El periodismo liberado de lo políticamente correcto. CEU Ediciones.

Gamson, W.A. (1989). News as framing. American Behavioral Scientist, 33(2), 157-161. https:// doi.org/10.1177/0002764289033002006

Gamson, W. A. (1992). Frontiers in social movement theory. Yale University Press.

Graber, D.A. (1989). Content and meaning. What's it all about? American Behavioral Scientist, 33(2), 144-152. https://doi.org/10.1177/0002764289033002004

Hänggli, R. (2020). The origin of dialogue in the news media. Palgrave Macmillan. https://doi. org/10.1007/978-3-030-26582-3 6

Igartua, J.J. y Humanes, M.L. (2004). Teoría e investigación en comunicación social. Editorial Síntesis.

Igartua, J.J. (2006). Métodos cuantitativos de investigación en comunicación. Editorial Bosch.

Instituto Nacional de Estadística e Informática, INEI (enero de 2020). Perú: estimaciones y proyecciones de población por departamento, provincia distrito, 2018-2020 (boletín especial n ${ }^{\circ}$ 26). https://www.inei.gob.pe/media/MenuRecursivo/publicaciones_digitales/Est/Lib1715/libro.pdf

Instituto Nacional de Estadística e Informática, INEI (agosto de 2018). Perú: perfil sociodemográfico. https://www.inei.gob.pe/media/MenuRecursivo/publicaciones_digitales/Est/Lib1539/

Ingrassia, P. (2020). La constitución de la violencia de género como problema público y los frames sobre aborto: revisión crítica de antecedentes y propuesta de análisis. Austral Comunicación, 9(2), 519-551. https://doi.org/10.26422/aucom.2020.0902.ing

Ipsos Global Advisor (17 de agosto de 2020). Miradas globales sobre el aborto. Ipsos. https:// www.ipsos.com/es-pe/miradas-globales-sobre-el-aborto

Leeper, T.J. y Slothuus, R. (2019). How the news media persuades: framing effects and beyond. En B. Grofman, E. Suhay y A. Trechsel (Eds.), The Oxford Handbook of Electoral Persuasion (pp. 55-73). Oxford University Press. https://doi.org/10.1093/oxfordhb/9780190860806.013.4

Luhmann, N. (2000). La realidad de los medios de masas. Anthropos Editorial.

McCombs, M.E. (1996). Influencia de las noticias sobre nuestras imágenes del mundo. En J. Bryant y D. Zillmann (Coords.): Los efectos de los medios de comunicación. Investigaciones y teorías (pp. 13-34). Paidós.

McCombs, M.E. y Shaw, D.L. (1972). The agenda-setting function of mass media. Public Opinion Quarterly, 36(2), 176-187. https://doi.org/10.1086/267990

Morán Faúndes, J.M. (2020), El dispositivo de la vida: cigotos, embriones y fetos en las políticas reproductivas. Anduli, Revista Andaluza de Ciencias Sociales, (19), 35-57. https://doi. org/10.12795/anduli.2020.i19.02 
Odriozola-Chéné, J., Gutiérrez-Atala, F., Domínguez-Panamá, J. J. y Pérez-Arozamena, R. (2019). Las relaciones de las influencias en los procesos de producción informativa y sus efectos en la calidad periodística. Una visión desde Latinoamérica. Cuadernos.info, (44), 119-134. https://doi. org/10.7764/cdi.44.1297

Oh, S.-K. y Hudson, J. (2017). Encuadres y reencuadres de los disturbios en LA en 1992: un estudio de las minorías desde los encuadres de Los Angeles Times y sus lectores. Revista de Comunicación, 16(2), 123-146. https://doi.org/10.26441/RC16.2-2017-A6

Pedrazzini, A. (2011). La relación verbal-visual en la portada de la prensa cotidiana: el caso atípico de Página/12. Razón y Palabra, (77). http://www.razonypalabra.org.mx/varia/77\%20 3a\%20parte/38 Pedrazzini_V77.pdf

Piñeiro-Naval, V. y Mangana, R. (2019). La presencia del framing en los artículos publicados en revistas hispanoamericanas de comunicación indexadas en Scopus. Palabra Clave, 22(1), 117142. https://doi.org/10.5294/pacla.2019.22.1.6

Price, V., Tewksbury, D. y Powers, E. (1997). Switching trains of thought: the impact of news frames on readers' cognitive responses. Communication Research, (24), 481-506. https://doi. org $/ 10.1177 / 009365097024005002$

Sádaba, T. (2007). Framing: el encuadre de las noticias. La Crujía.

Sánchez Vilela, R. (2013). Medios de comunicación y cultura: Frame analysis para el estudio de la recepción. Revista Luciérnaga, 5(10), 41-54. https://bit.ly/2WTJzbV

Scheufele, D. A. y Tewksbury, D. (2007). Framing, agenda-setting and priming: the evolution of three media effects models. Journal of Communication, (57), 9-20. https://doi.org/10.1111/j.14602466.2006.00326 5.x

Shoemaker, P.J. y Reese, S.D. (1996). Mediating the message. Theories of influences on mass media content. Longman Publishers.

Suenzo, F., Boczkowski, P. J., y Mitchelstein, E. (2021). La crisis de la prensa escrita: una revisión bibliográfica para repensarla desde Latinoamérica. Cuadernos.info, (47), 1-25. http:// dx.doi.org/10.7764/cdi.47.1867

Vreese, C.H., Peter, J. y Semetko, H.A. (2001). Framing politics at the launch of the euro: a crossnational comparative study of frames in the news. Political Communication, 18(2), 107-122. https://doi.org/10.1080/105846001750322934 